\title{
POLIFONIA COMO EFEITO DE SENTIDO: DESDOBRAMENTOS SEMIÓTICOS
}

\author{
POLYPHONY AS EFFECT OF MEANING: \\ SEMIOTIC DEVELOPMENTS
}

\author{
Marcos Rogério Martins Costa \\ USP - Universidade de São Paulo ${ }^{1}$
}

RESUMO: Este estudo pretende discutir quais são os elementos constitutivos de um romance polifônico. Para tanto, utilizamos os recursos analíticos oferecidos pela semiótica discursiva somados aos princípios filosóficos bakhtinianos, em particular o conceito de polifonia, tal como formulado por Bakhtin (1997). Esse arcabouço teórico sustenta nosso exame dos mecanismos de construção do sentido no romance Crime e castigo, de Fiódor Dostoiévski. Como método para esta investigação, apresentamos trechos selecionados do romance supracitado e perscrutamos o efeito de sentido de polifonia por meio do percurso gerativo do sentido (GREIMAS; COURTÉS, 2008). Afirmamos, semioticamente, a polifonia como efeito de sentido depreensível desde as estruturas profundas até a sua manifestação no nível discursivo. Portanto, nosso estudo se configura como uma análise interdisciplinar, que busca um diálogo entre a filosofia bakhtiniana e a semiótica da Escola de Paris.

PALAVRAS-CHAVE: polifonia; semiótica; filosofia bakhtiniana; efeito de sentido.

\begin{abstract}
This study aims at discussing which are the components of a polyphonic novel. To achieve that we used the analytical resources offered by discursive semiotics and also the philosophical principles of Bakhtin, especially the concept of polyphony, as formulated by Bakhtin (1997). This theoretical base supports our examination of the mechanisms of construction of meaning in the novel Crime and punishment, by Fyodor Dostoevsky. As a method for this investigation, we present excerpts of the novel abovementioned and investigated the effect of meaning polyphony through generative process of meaning (GREIMAS; COURTÉS, 2008). We assure, semiotically, the polyphony as an effect of meaning inferred from the deep structures to its manifestation in the discursive level. Therefore, our study consists in an interdisciplinary analysis, which aims a dialogue between Bakhtin's philosophy and Paris School semiotics.
\end{abstract}

KEYWORDS: polyphony; semiotics; bakhtin's philosophy; effect of meaning.

\section{Introdução}

Isto pode ser expresso assim: os contrários se encontram, se olham mutuamente, refletem-se um no outro, conhecem e compreendem um ao outro. (BAKHTIN, 1997, p. 179).

\footnotetext{
${ }^{1}$ Mestrando no Programa de Pós-Graduação em Semiótica e Linguística Geral da Universidade de São PauloUSP, São Paulo, São Paulo, Brasil; bolsista CNPq; marcos.rogerio.costa@usp.br
} 
Em uma carta destinada a seu amigo Vadim Kojínov, em 30 de julho de 1961, Mikhail Bakhtin (1895-1975) explicita que o conceito de polifonia, "mais que qualquer outra coisa, suscitou objeções e mal-entendidos". ${ }^{2}$ Essa observação pode ser confirmada pela ampla difusão editorial das obras de Bakhtin e de seus comentadores em várias partes do mundo. Em solo brasileiro, há revistas especializadas em temáticas bakhtinianas, como a Bakhtiniana, revista da Pontifícia Universidade Católica de São Paulo (PUC-SP), que publica, desde 2008, artigos científicos, resenhas e traduções a respeito desse temário. ${ }^{3}$ No que se refere ao conceito de polifonia, observamos que esse termo possui muitas concepções, sendo algumas delas diferentes da proposta do filósofo da linguagem russo.

Temos preceituações teóricas que consideram a polifonia como um fenômeno que possibilita ao locutor apresentar diferentes pontos de vista em um determinado enunciado, como propõe Ducrot (1987), ou, ainda, prismas psicanalíticos de linha lacaniana que concebem esse termo como caracterização do inconsciente. ${ }^{4}$ Entre outras acepções, a proposta bakhtiniana traça a seguinte concepção de polifonia:

A essência da polifonia consiste justamente no fato de que as vozes, aqui, permanecem independentes e, como tais, combinam-se numa unidade de ordem superior à da homofonia. E se falarmos de vontade individual, então é na polifonia que ocorre a combinação de várias vontades individuais, realizase a saída de princípio para além dos limites de uma vontade. (BAKHTIN, 1997, p. 21).

Como podemos notar nesse excerto, não há uma clara definição do conceito de polifonia (como as personagens podem ser independentes? Como ocorre essa combinação de vontades individuais? Por que as vozes se combinam numa unidade superior à da homofonia?), o que se perpetua durante toda a explanação de Bakhtin (1997). Morson e Emerson (2008, p. 248) discutem essa inexatidão epistêmica do conceito a partir do próprio postulado do filósofo russo:

Para começar, Bakhtin nunca define explicitamente a polifonia. No primeiro capítulo de Problemas da Poética de Dostoiévski (e intitulada, na edição de 1929, Problemas da Arte Criativa [ou Criatividade] de Dostoiévski), ele reexamina seletivamente a literatura crítica sobre Dostoiévski e, depois de cada sumário, especifica as suas razões para concordar ou discordar. Essa exposição fragmentada leva à repetição de alguns pontos e à ambiguidade em relação a outros. No final do capítulo, ele forneceu muita informação sobre polifonia, mas nenhuma definição explícita dela. Se esperamos que essa omissão seja corrigida nos capítulos subsequentes, ficamos

\footnotetext{
${ }^{2}$ Carta citada conforme a nota dos editores a "K pererabotke knigi o Dostoiévskom" na Coleção russa das obras de Bakhtin (1979, p. 404). Documento citado por Morson e Emerson (2008, p. 247).

${ }^{3}$ Bakhtiniana: revista de estudos do discurso (ISSN 2176-4573) do Programa de Pós-Graduação em Linguística Aplicada e Estudos da Linguagem - PUC-SP, Grupo de Pesquisa do CNPq: Linguagem, Identidade e Memória.

${ }^{4}$ Brait e Campos $(2009$, p. 17) ressaltam que também devemos atentar para as origens das traduções, visto que a difusão do pensamento bakhtiniano e de seus conceitos é feita de forma indireta, principalmente no Brasil, onde temos tradução a partir do inglês ou do francês na maioria dos casos. Assim, "pode acontecer a inclusão de conceitos estranhos ao conjunto dos trabalhos do Círculo [de Bakhtin], como intertextualidade, ou deslizamentos, reduções, adaptações e expansões de significação de determinados termos-chave como heteroglosia, dialogismo, polifonia, gêneros do discurso, entre outros" (BRAIT; CAMPOS, 2009, p. 17, grifo do autor).
} 
desapontados. O resto do livro discute as implicações da polifonia para representação do herói e das ideias, para a forma dos entrechos e o uso da linguagem bivocalizada, mas Bakhtin nunca especifica exatamente o que é e o que não é constitutivo da polifonia per se.

Tendo em vista esse panorama, o conceito de polifonia provocou muitos equívocos. Desse modo, desfaçamos alguns deles em benefício de uma maior clareza a respeito do nosso objeto de estudo. Em primeiro lugar, a polifonia não é um atributo de todos os romances e, segundo Bakhtin, Dostoiévski foi o criador do romance polifônico - o que justifica o nosso interesse por esse escritor. No entanto ele não foi o único a utilizar esse recurso, embora o fenômeno ainda seja relativamente raro no panorama literário, segundo Morson e Emerson (2008) e Frank (2003).

Em segundo lugar, polifonia não deve ser confundida com heteroglossia, que é um fenômeno que descreve uma multiplicidade de estilos de discurso em uma língua, ao passo que a polifonia, como pretendemos aqui demonstrar, apresenta um outro tipo de posicionamento do autor e de suas personagens dentro da esfera discursiva literária.

Em terceiro lugar e principalmente, o conceito de polifonia não torna ausente $o$ ponto de vista do autor. Se essa questão não for pontuada, pode haver um equívoco na apreensão da noção de polifonia, pois poderia ser considerado que, se as personagens possuem tamanha independência do autor, logo, este não apresentaria seu ponto de vista. Todavia essa crítica não se sustenta, posto que Bakhtin disse reiteradamente que o autor polifônico - principalmente Dostoiévski - não deixa de expressar suas ideias e valores: "a consciência do criador do romance polifônico [Dostoiévski] está constantemente em todo esse romance, onde é ativa ao extremo" (BAKHTIN, 1997, p. 68). Podemos notar, então, não uma renúncia a ele próprio ou à sua consciência, mas um novo posicionamento do autor, como averiguaremos em nossa análise por meio do exame do campo de presença do efeito de polifonia.

O quarto mal-entendido diz respeito à unidade do romance. A obra polifônica não carece de unidade - como se poderia presumir em uma leitura superficial de Problemas da poética de Dostoiévski -, posto que, segundo a própria proposta bakhtiniana, uma obra sem algum tipo de unidade seria simplesmente uma obra deficiente, visto que não constituiria uma arquitetônica eficiente. ${ }^{5}$ De acordo com Morson e Emerson (2008, p. 249), “a polifonia requer um tipo diferente de unidade, que Bakhtin chama de 'unidade de ordem superior'”, a qual é alvo de nossa investigação.

Outro equívoco é a separação polarizante entre forma e conteúdo nas análises que procuram elaborar o conceito de polifonia. Como observa Todorov (1984), um dos posicionamentos de Bakhtin e seu Círculo consiste na recusa sistemática em separar forma e conteúdo. A tentativa do filósofo da linguagem russo de aplicar esse princípio está no cerne da obra Problemas da poética de Dostoiévski. Dessa forma, todo ato estético é também ético, um se refrata no outro. Isso ocorre porque, como propõe Bakhtin (2010), todo ato ético implica ação, ao mesmo tempo em que participa do que realiza e faz integrar o ser ao realizado. Assim, através desse ato, o sujeito se reconhece e é reconhecido.

Como podemos notar, a filosofia bakhtiniana possui seu próprio instrumental teórico e metodológico (BAKHTIN, 2009), que, até pouco tempo atrás, ficou restrito às

\footnotetext{
${ }^{5}$ Conforme Bakhtin (1997, p. 6), “o mundo de Dostoiévski pode afigurar-se um caos e a construção dos seus romances algum conglomerado de matérias estranhas e princípios incompatíveis de formalização. Só à luz da meta artística central de Dostoiévski por nós formulada podem tornar-se compreensíveis a profunda organicidade, a coerência e a integridade de sua poética.".
} 
análises literárias. Contudo, seja pelo percurso histórico caudaloso de sua transmissão/tradução, seja pelo árduo resgate dos arquivos soviéticos ${ }^{6}$, houve uma diversificação dos prismas teóricos que passaram a consultar a obra bakhtiniana.

Diferentes campos de pesquisa começaram a dialogar com essa filosofia, como é o caso da antropologia, da psicologia, da psiquiatria, da sociologia e da própria linguística. A linguística, campo que acolhe a nossa pesquisa, passou a compreender a filosofia bakhtiniana no momento em que ampliou o escopo de seus estudos em direção ao nível discursivo, transfrástico. Esse espaço linguístico é o que interessa ao nosso estudo e o que estimula nosso ingresso nas trilhas bakhtinianas, pois é a área em que a semiótica busca seu sentido. Além disso, conforme salienta Barros (2011, p. 1), "Bakhtin antecipa de muito as principais orientações da linguística moderna, principalmente no que respeita aos estudos da enunciação, da intenção verbal e das relações entre linguagem, sociedade e história e entre linguagem e ideologia".

Portanto este estudo visa perscrutar o instigante e polêmico conceito bakhtiniano de polifonia. No entanto, não almejamos somente (re)examinar o conceito teoricamente, mas também discutir sua aplicação à obra dostoievskiana, com destaque para 0 romance Crime e castigo, corpus de nossa investigação.

Para que esse objetivo fosse alcançado, recorremos, além de a Bakhtin e seu Círculo, a uma teoria da significação que atenta para as inovações e para a complexidade da sociedade, e que opera com as categorias de contradição, excesso, inacabamento, limiar, valoração e reelaboração. Mantendo esse princípio, optamos pela semiótica de linha francesa, pois, como ciência da significação, possibilita perscrutar os entrelaçamentos, os confrontos e as multiplicidades que constroem e sustentam os nossos discursos.

Por conseguinte, conciliando, de um lado, a filosofia bakhtiniana e, de outro, a semiótica da Escola de Paris, nosso interesse científico foi investigar a arquitetônica da prosa dostoievskiana a fim de resgatar o conceito bakhtiniano de polifonia e procurar desenvolvê-lo, para assim extrair dele "a propriedade comum a todas as semióticas, o conceito de sentido" (GREIMAS; COURTÉS, 2008, p. 456).

\title{
1. Polifonia como efeito de sentido: desdobramentos semióticos
}

\begin{abstract}
E na verdade, os obstáculos à polifonia são imensos, como Bakhtin admite eis por que tanta história literária e social foi requerida antes que ambas fossem suplantadas. O grande feito de Dostoiévski foi descobrir um modo de encontrar as suas personagens tão não finalizáveis como outros e envolvê-las num genuíno diálogo aberto-acabado. (MORSON; EMERSON, 2008, p. 257).
\end{abstract}

Começamos a nossa discussão apresentando as dificuldades de abordar esse conceito bakhtiniano e comentamos alguns mal-entendidos que o cercam. Ainda não expusemos aquele que talvez seja o maior de todos os mal-entendidos sobre polifonia: será que a polifonia é um relativismo teórico? Bakhtin (1997, p. 69, grifo do autor) já previa e alertava sobre esse mal-entendido:

\footnotetext{
${ }^{6}$ Lembramos aqui os estudos de Clark e Holquist (1984) e o de Todorov (1984).
}

Disponível em: http://seer.fclar.unesp.br/casa 
Não vemos qualquer necessidade de dizer especialmente que o enfoque polifônico nada tem em comum com o relativismo (e igualmente com o dogmatismo). Devemos dizer que o relativismo e o dogmatismo excluem igualmente qualquer discussão, todo diálogo autêntico, tornando-o desnecessário (o relativismo) ou impossível (o dogmatismo). Já a polifonia enquanto método artístico situa-se inteiramente em outro plano.

Como notamos nessa citação, a polifonia também é um método artístico e está situada no próprio plano da criação estética. Consideramos, a partir dos pressupostos da semiótica discursiva, a polifonia como um efeito de sentido que não escapa de um campo de presença. ${ }^{7}$ No entanto, diante dessa orientação bakhtiniana, salientamos que esse conceito também remete a um método de criação estética, isto é, a uma posição singular do autor necessária para criar e recriar esse efeito de sentido específico.

Nossa orientação teórica não é isolada. Morson e Emerson (2008, p. 250) também estipularam critérios para a apreensão desse conceito:

Na nossa interpretação de Bakhtin, dois critérios estreitamente correlatos são constitutivos da polifonia: uma percepção dialógica da verdade e uma posição especial do autor necessária para a visualização e a transmissão dessa percepção da verdade. De fato, esses dois critérios são aspectos do mesmo fenômeno, a "ideologia modeladora da forma" da obra polifônica. Só se pode separá-los para fins de análise.

A explicação desses autores é baseada na noção de ideologia. Já a nossa proposta procura resposta na tensividade e na narratividade, direcionamentos da abordagem semiótica, a qual nos afiliamos. Salientamos, assim, que nossa pesquisa, atrelada aos desdobramentos tensivos e discursivos da semiótica da Escola de Paris, procura, de um lado, as dependências mútuas que sustentam o campo de presença do efeito de polifonia, e, de outro, flagrar como o sujeito estético, no caso, o autor-criador Dostoiévski, instaura o efeito de polifonia no enunciado. Temos, então, uma via de mão dupla: uma que vai do enunciado para a enunciação e outra que faz o caminho inverso.

Acrescentamos, ainda, que nosso intuito é compatível com a perspectiva bakhtiniana acima apresentada. Primeiro, porque não estamos simplesmente aceitando o signo linguístico, no caso a obra literária dostoievskiana, como uma "entidade psíquica de duas faces" (SAUSSURE, 1970, p. 80); supomos e dispomo-nos a analisar a presença de um sujeito que viabiliza o sentido das coisas segundo uma aparência - a qual dispõe de uma dimensão significante - e uma imanência - que guarda a dimensão do significado. É, então, possível perscrutar o pensamento bakhtiniano a partir de uma análise semiótica, como propõe Discini (2009, p. 595):

Saussure e Bakhtin estão, cada qual à sua moda, nas duas pontas do pensamento sobre a linguagem ora contemplado com vistas a examinar compatibilidades de pontos de vista entre eles. Esses dois polos somente

\footnotetext{
${ }^{7}$ Segundo Greimas e Courtés (2008, p. 155), efeito de sentido é uma expressão tomada de G. Guillaume, que corresponde "à impressão de 'realidade' produzida pelos nossos sentidos, quando entram em contato com o sentido, isto é, com uma semiótica subjacente". Desse modo, "situado na instância da recepção, o efeito de sentido corresponde à semiose, ato situado no nível da enunciação, e à sua manifestação que é o enunciadodiscurso" (GREIMAS; COURTÉS, 2008, p. 156).
} 
serão postos em cotejo se pensados na cadeia discursiva estabelecida com mediação de Hjelsmlev e Greimas. Assim as ditas compatibilidades deverão ser vistas como base fortalecedora dos princípios teóricos e metodológicos da teoria da significação, cuja preocupação é "[...] explicitar, sob a forma de construção conceitual, as condições da apreensão e da produção do sentido" (GREIMAS; COURTÉS, 2008, p. 455): a semiótica ${ }^{8}$.

Além disso, não negligenciamos o mundo como um dado anterior ao indivíduo, visto que, como destaca ainda a autora, "Greimas e Courtés ressaltam a própria natureza como culturalizada e o mundo natural como o que está enformado e categorizado pelas línguas naturais" (DISCINI, 2009, p. 596). Isso corrobora a perspectiva bakhtiniana, que concebe a linguagem como o elo entre a consciência humana e o mundo: "Um signo não existe apenas como parte de uma realidade; ele também reflete e refrata uma outra. Ele pode distorcer essa realidade, ser-lhe fiel, ou apreendê-la de um ponto de vista específico, etc." (BAKHTIN; 2009, p. 33-34).

Além disso, como discute Zilberberg (2011, p. 16), "a casa do sentido é vasta o bastante para acolher tanto o contínuo, quanto o descontínuo, mesmo porque nem este nem aquele fazem sentido por si mesmos, mas apenas por sua colaboração". Desse modo, entendemos que ela também acolherá o acabamento (limite) e o inacabamento (limiar), principalmente este. Isso porque, seja em nossas produções fônicas mais corriqueiras, seja nos discursos mais monitorados, todos estamos traçando linhas pontilhadas em nossos discursos, pistas que, ora estão no não dito (pressupostos, implicaturas conversacionais etc.), ora nas marcas enunciativas (gestos, entonação, voz etc.).

Compreendidos o sujeito, o contexto e o inacabamento, nossa proposta semiótica procurou perscrutar o efeito de sentido de polifonia tanto quanto o seu método de criação estética. Para deslindar os elementos constitutivos dessa noção bakhtiniana, avancemos rumo à análise.

\section{O método de criação estética da polifonia: a relação entre autor-criador e herói}

Bakhtin (1997, p. 5) atribui a Dostoiévski o título de "criador do romance polifônico", apontando que, na obra desse escritor, a configuração das personagens as constitui como ideólogas, ou seja, personas que defendem as próprias vozes, as quais não correspondem necessariamente às do autor. "O herói dostoievskiano não é apenas um discurso sobre si mesmo e sobre seu ambiente imediato, mas também um discurso sobre o mundo: ele é apenas um ser consciente, é um ideólogo" (BAKHTIN, 1997, p. 77).

Partindo desse pensamento, propomos que as personagens de Crime e castigo - corpus de nosso estudo - possuem interdependência e espaço para a realização de seus próprios discursos. Essas personagens se entrelaçam na escrita do romance, produzindo distintos modos de presença, os quais podem ou não convergir entre si. Ressaltamos, ainda, que a mesma inclinação pode ser observada entre os modos de presença do autor com relação aos de suas personagens, se cotejados, pois tanto o autor como elas se encontram em equipolência discursiva na arquitetônica romanesca, o que preanuncia um método singular de criação estética.

\footnotetext{
${ }^{8}$ Discini (2009) faz referência, no excerto, à obra de Greimas e Courtés (2008).
}

Disponível em: http://seer.fclar.unesp.br/casa 
Desse modo, dentro do plano artístico de Dostoiévski, suas principais personagens não são objeto do discurso do autor, como ocorria nos romances monológicos, mas os próprios sujeitos desse discurso diretamente significante. As personagens Raskólnikov (Crime e castigo), Ivan Karamázov (Os irmãos Karamázov) e Aleksiéi (Um jogador) são donos de suas próprias vozes - em diferentes graus -, não agindo meramente como marionetes da voz de um autor onipotente. Dostoiévski não fala do herói, mas com o herói. $\mathrm{O}$ autor não quer retratar a coisificação do homem, mas, antes, relatar o homem no homem, ou seja, o realismo no mais alto sentido (cf. BAKHTIN, 1997, p. 61).

Acreditamos que a análise semiótica possibilita a investigação dos mecanismos de construção da polifonia dentro da obra dostoievskiana, bem como permite observar como se estabelece o grande diálogo no romance polifônico. Para tanto, adentrando esse universo das multiplicidades de vozes, procuramos investigar os elementos que formam o eixo do limiar, no qual se constitui o romance polifônico, visto que ele é formado pela "interação de consciências eqüipolentes e interiormente inacabadas" (BAKHTIN, 1997, p. 153).

Dentre os elementos contemplados em nossa análise semiótica, destacamos a heterogeneidade constitutiva e o dialogismo, na medida em que remetem à inconclusibilidade, efeito de sentido que resulta da relação autor-herói na obra polifônica. De acordo com Discini (2008, p. 72-13), "a polifonia viabiliza o herói (personagem) que fala com o autor e não é falado por ele; o herói com autonomia de voz e constituído como avesso à biografia "no sentido do ido e do vivido, , o herói carnavalizado".

Entendendo a proposta bakhtiniana e relacionando-a com a observação de Discini (2008), definimos o herói dito polifônico como aquele que não coincide com um acabamento em sua totalidade, isto é, ele não converge com as expectativas de si mesmo, nem com as do seu autor-criador. Este, por sua vez, não está circunscrito ao dogmatismo da palavra, mesmo tendo o domínio dos mecanismos de enunciação. O autor-criador de um romance polifônico - também definamos - não é apenas coparticipante no ato de narrar, ele é também um viabilizador e articulador das brechas polifônicas.

Desse modo, em acordo com Discini (2008, p. 73), “estamos diante do herói e do autor dialógicos não somente porque são dados em coparticipação no ato de narrar, mas porque se entrecruzam as entonações das vozes na orientação responsiva do discurso do herói em relação ao do seu criador e vice-versa".

Em termos semióticos, o sujeito, seja o da enunciação (autor-criador), seja o do enunciado (herói), é apresentado como um ator do inacabamento, visto que não sustenta, de maneira convencional, as posições previstas na enunciação: delegador de vozes (sujeito da enunciação) e voz delegada (sujeito do enunciado). Um responde ao outro em diferentes graus e de modos distintos, ou seja, não há uma subordinação entre essas vozes que faça uma "imagem objetificada do herói":

A voz do herói sobre si mesmo e o mundo é tão plena como a palavra comum do autor; não está subordinada à imagem objetificada do herói como uma de suas características mas tampouco serve de intérprete da voz do autor. Ele possui independência excepcional na estrutura da obra, é como se soasse ao lado da palavra do autor, coaduando-se de modo especial como ele com as vozes plenivalentes de outros heróis. (BAKHTIN, 1997, p.5).

\footnotetext{
${ }^{9}$ Discini (2008, p. 73) remete a Bakhtin (1997, p. 23).
} 
Portanto, a partir da terminologia semiótica e de seus recursos analíticos, definimos que, dentro de um romance polifônico, o ator considerado polifônico é ator do enunciado, o herói bakhtiniano ou a personagem, segundo a tradição literária. Polifônico também é o enunciado, visto que manifesta o efeito de sentido de polifonia. Já o ator da enunciação, o autor-criador segundo a proposta bakhtiniana, é o viabilizador da polifonia, visto que fundamenta sua criação - isto é, seus mecanismos de enunciação e sua construção estética - em um romance polifônico, gênero discursivo escolhido, desenvolvido e, então, concretizado em sua obra romanesca.

O conceito de polifonia, dessa forma, dispõe um arranjo singular no tabuleiro da enunciação, o que desperta o interesse da semiótica no estudo dessa noção bakhtiniana, principalmente o deste estudo. Portanto, foi nossa meta observar e depreender como essas vozes dos atores, principalmente o do enunciado, se engendram dentro de um romance polifônico.

\section{Análise de trechos de Crime e castigo: sob a perspectiva do ator Raskólnikov}

Para mantermo-nos fiéis à pretensão científica de Hjelmslev (1975, p. 70): "uma tal descrição pressupõe que os signos - que são em número ilimitado - também são suscetíveis no que diz respeito ao seu conteúdo, de serem explicados e descritos com a ajuda de um número limitado de figuras", resgatamos junto a Greimas e Courtés (2008) o suporte teórico para analisar o romance Crime e castigo: o percurso gerativo de sentido. Como ponto de vista para analisar os programas narrativos existentes dentro dessa obra romanesca, elegemos a perspectiva do protagonista Raskólnikov.

Crime e castigo apresenta a trama de Raskólnikov, ${ }^{10}$ um ex-estudante de direito, que passa por dificuldades financeiras e resolve reverter essa situação quando toma uma decisão diante de uma ideia que há muito tempo o atormentava. Ele vive como um miserável em um quartinho alugado, sendo explorado por uma velha usurária, Aliena Ivánovna, que cobra juros altos pelas minguadas moedas que lhe empresta sob a penhora de objetos familiares. A família do protagonista se resume à sua mãe idosa, Pulkhéria Ivánovitch Vakhrúchin, e à sua irmã, Avdótia Románovna Dúnia, que era, até pouco tempo, governanta, porém, devido ao assédio de seu patrão, o senhor Svidrigáilov, teve de se demitir.

Todavia, a esposa de Svidrigáilov, ao descobrir que era o marido quem assediava a ex-governanta, sente-se em débito moral com a moça, visto que a difamara pela cidade e, então, trata de arranjar um casamento com um parente distante, um homem mais velho, mas muito rico. O casamento poderia trazer uma boa condição tanto para Dúnia como para sua família, em especial para seu irmão Raskólnikov, o qual não deseja o sacrifício da irmã.

Todos esses fatos elencados povoam e afligem a mente do estudante que, com sua agudeza e erudição rara, desenvolvia, há algum tempo, uma ideia-teoria a qual, diante dessa conjuntura, impele-o a tomar uma decisão: cometer um assassinato.

Essa ideia-teoria desenvolvida por Raskólnikov divide os homens em duas classes essenciais: a dos ordinários e a dos extraordinários. A primeira classe abarca o

${ }^{10}$ O nome Raskólnikov evoca um dissidente religioso cismático da Rússia, um raskólnik; e o radical raskol
significa cindido. Essa polissemia do nome do protagonista é bem relevante ao público leitor, principalmente ao
russo, visto que já traz ao ator uma construção figurativo-temática esperada: a de um ser cindido. Disponível em: http://seer.fclar.unesp.br/casa 
homem conservador por natureza e, portanto, mantenedor das estruturas sociais, sendo, muitas vezes, impossibilitado pela sua própria natureza de realizar uma ação criminosa. Já a segunda categoria acolhe aquele que tem a possibilidade e a capacidade de dizer algo novo, de fazer algo inusitado. O sujeito dessa última classe se "precisar passar por cima ainda que seja de um cadáver, [...] ele pode se permitir, no seu interior, na sua consciência passar por cima do sangue - todavia, conforme a ideia e suas dimensões" (DOSTOIÉVSKI, 2009, p. 270).

O estudante sustenta essa teoria sob o substrato das experiências históricas dos grandes líderes que foram, em sua maior parte, grandes sanguinários. Raskólnikov usa como maior exemplo Napoleão, que, para consolidar a classe burguesa, tingiu a terra de vermelho e, apesar disso, "a história o absolveu" (BEZERRA, 2009, p. 12). Logo, se a história age dessa forma, se as engrenagens são essas, por que ele, Raskólnikov, não poderia matar uma velha usurária para o bem de sua ideia? Essa indagação possivelmente trilha a lógica da teoria do estudante, a qual lhe serve como trampolim para cometer o assassinato. Aliás, destacamos ter sido esse um assassinato duplo seguido de roubo, pois Lisavieta, irmã da velha agiota, após chegar repentinamente à casa desta e encontrar os móveis fora do lugar e o estudante ao lado do corpo ensanguentado da irmã, também foi morta.

Tendo observado rapidamente os fatos e raciocínios que motivam o protagonista ao latrocínio, podemos adentrar a análise semiótica das estruturas desse romance. Barros (2005) explica que a semiótica concebe o plano do conteúdo sob a forma de um percurso gerativo para construir o sentido do texto. Desse modo, a noção de percurso gerativo do sentido é de grande importância para a teoria semiótica. A autora resume essa proposta de investigação e produção do sentido nos seguintes termos:

a) o percurso gerativo do sentido vai do mais simples e abstrato ao mais complexo e concreto; b) são estabelecidas três etapas no percurso, podendo cada uma ser descrita e explicada por uma gramática autônoma, muito embora o sentido do texto dependa da relação entre os níveis; c) a primeira etapa do percurso, a mais simples e abstrata, recebe o nome de nível fundamental ou das estruturas fundamentais e nele surge a significação como uma oposição semântica mínima; d) no segundo patamar, denominado nível narrativo ou das estruturas narrativas, organiza-se a narrativa, do ponto de vista de um sujeito; e) o terceiro nível é o do discurso ou das estruturas discursivas em que a narrativa é assumida pelo sujeito da enunciação (BARROS, 2005, p. 13).

Por meio desses pressupostos teóricos, procuramos investigar as estruturas semionarrativas e discursivas do romance dostoievskiano Crime e castigo para constatar a polifonia que se instaura nesse texto. Assim, a partir das ferramentas oferecidas pelo percurso gerativo de sentido, podemos obter "a disposição de seus componentes uns em relação aos outros, e isso na perspectiva da geração", isto é, "podendo todo objeto semiótico ser definido segundo o modo de sua produção" (GREIMAS; COURTÉS, 2008, p. 232).

No nível das estruturas fundamentais, é determinada a oposição ou as oposições semânticas a partir das quais o sentido é construído ao longo do texto. Em Crime e castigo, a categoria semântica fundamental que podemos apreender é natureza vs. cultura. Porém, dentro dessa grande categoria semântica, que tende a nortear todas as relações semânticas do texto, surge filiada outra categoria: identidade vs. alteridade. Dessa maneira, no nível fundamental, sustentam-se as seguintes categorias: natureza, identidade vs. alteridade e cultura. Como podemos observar neste trecho da obra: 
[...] Precisava decidir-se a qualquer custo, fosse lá pelo que fosse, ou...

Ou renunciar totalmente à vida! - gritou de repente com furor -, aceitar docilmente o destino como ele é, de uma vez por todas, e sufocar tudo em mim, abrindo mão de qualquer direito de agir, viver e amar!

Compreende, será que compreende, meu caro senhor, o que significa não ter mais para onde ir? - lembrou-se num átimo da pergunta feita ontem por Marmieládov -, porque é preciso que toda pessoa possa ir ao menos a algum lugar...” (DOSTOIÉVSKI, 2009, p. 61).

Embora o jovem tenha decidido ir à casa da velha usurária e cometer o assassinato, Raskólnikov não renuncia totalmente à vida, isto é, ao polo da identidade, da natureza. Desse modo, de forma geral, o que notamos de singular na trama é a mobilidade peculiar da orientação fórica, que permite a Raskólnikov, bem como a cada membro da narrativa, expor diversas determinações axiológicas, não havendo, portanto, uma categoria fundamental fixa como eufórica ou disfórica durante toda a trama.

Essa característica é um dos alicerces que começam a ser erguidos para a construção do efeito de polifonia na obra dostoievskiana, visto que, não tendo um centro dominante de orientação fórica, o autor-criador permite aos seus atores-enunciados certa autonomia, fator indispensável para que haja uma relação equipolente entre as vozes no nível discursivo, caracterizando, assim, a polifonia.

Notamos, portanto, haver no romance duas categorias semânticas relativamente heterogêneas, que são tratadas como se fossem dois esquemas de um único microuniverso discursivo. Nesse contexto, consideramos existir uma sintaxe fundamental que assevera alternativamente como verdadeiros os dois termos contrários desse universo de discurso, ou seja, tanto o polo da cultura, alteridade ("aceitar docilmente o destino como ele é"), como o da natureza, identidade ("direito de agir, viver e amar"). É sustentada, dessa forma, uma confluência fórica no nível fundamental. Assim sendo, Raskólnikov vai se apresentar no modo de presença, no nível discursivo, como um herói da mistura, visto que ele vai tanger os dois polos simultaneamente. ${ }^{11}$

No segundo patamar, o nível das estruturas narrativas, Barros (2005, p. 15) nos lembra que "os elementos das oposições semânticas fundamentais assumidos como valores por um sujeito circulam entre sujeitos graças à ação também de sujeitos", ou seja, não é mais o caso de afirmar ou de negar conteúdos, antes, de transformar, pela ação do sujeito, enunciados de estado. É essa transformação de enunciados de estados que estudamos nesse nível.

\footnotetext{
${ }^{11} \mathrm{O}$ termo mistura, além da atribuição de termo técnico que designa um processamento da matéria, como pensado por Greimas (1983), constitui, dentro da perspectiva da semiótica tensiva, desenvolvida por Zilberberg (2011, p. 268), "uma das duas grandes operações da sintaxe extensiva, ou seja, a sintaxe referente aos estados de coisas. Diante de um objeto que vale antes de tudo pelo seu índice, elevado ou nulo, de composição com outros objetos, o sujeito, a partir do seu foco, opera triagens ou misturas. A solidariedade entre ambas as operações tem com consequência o fato de a triagem se processar necessariamente sobre uma mistura anterior, na exata medida em que uma mistura só pode ser considerada se incide sobre uma triagem anterior estabilizada". Logo, Raskólnikov, em relação a uma triagem estabilizada das consciências-ideias que o rodeiam, processa uma mistura, em que, ressaltamos, não há uma fusão de elementos, mas uma multiplicidade de consciências-ideias em diálogo. Denominamos, assim, como herói da mistura um ator do enunciado que conserva em si dois polos sêmicos distintos e diversos, os quais podem ser ainda divergentes.
} 
Depreendemos que, em Crime e castigo, não existe apenas um único programa narrativo, mas vários, os quais se estabelecem, principalmente, em relação polêmica. Dessa maneira, o protagonista Raskólnikov não se perpetua nem como um sujeito da aquisição de um objeto de valor, nem como um sujeito concernente à aquisição de um objeto de valor ele é tudo, simultaneamente. Nesses programas, em muitos casos, há um sincretismo de papéis actanciais, o que permite dizer que, no nível discursivo, apesar de o foco narrativo estar voltado para o sujeito Raskólnikov (narrativa dita em terceira pessoa), temos, na tessitura de Crime e castigo, outras tramas relativas a outros sujeitos-personagens que cruzam a trama de Raskólnikov. Portanto este último é invadido pelos outros sujeitos-personagens que, assim como ele, possuem voz para dialogar e vez para fazer-fazer. Esses atravessamentos de percursos narrativos podem ser observados no trecho abaixo:

Caramba, Zamiótov!... a delegacia!... E por que é que estão me intimando à delegacia? Cadê a intimação? Caramba!... eu confundi: a intimação foi da outra vez! Naquele momento eu também examinei a meia, mas agora... agora eu estava doente. E o que Zamiótov veio fazer aqui? Para que Razumíkhin o trouxe aqui?... - resmungava ele impotente, voltando a sentar-se no sofá. - O que é mesmo isso? Será que eu continuo delirando ou isso é verdade? Parece que é verdade... Ah, me lembrei: fugir! Fugir logo, sem falta, sem falta fugir! Sim... mas para onde? E onde está minha roupa? Não tenho botas! Recolheram! Esconderam! Compreendo! Mas, e o sobretudo - não distinguiram! Eis o dinheiro na mesa, graças a Deus! E eis a letra... Pego o dinheiro e vou embora, alugo outro quarto, eles não vão me achar!... É, mas e o serviço de informações de endereços? Vão achar! Razumíkhin acha. O melhor é fugir de vez... para longe... para a América, e me lixar para eles! E levar a letra... lá ela vai servir. Levar mais o quê? Eles pensam que estou doente! Eles nem sabem que estou podendo andar, he-he-he!... Pelo olhar deles percebi que estão sabendo de tudo! Eu só precisava descer a escada! Mas lá estão os guardas deles, os policiais! O que é isso, chá? Ah, olha sobrou cerveja, meia garrafa, fresca! (DOSTOIÉVSKI, 2009, p. 140).

Nesse excerto, notamos um encadeamento de programas narrativos possíveis, Raskólnikov faz uma análise de cada possibilidade de fuga, analisando a reação de cada um dos outros sujeitos ali presentes. Daí o outro invadir Raskólnikov à medida que o protagonista vai convocando os sujeitos (Zamiótov, Razumíkhin, policiais etc.) e as coisas (intimação, botas, dinheiro, chá, cerveja, etc.) que o rodeiam para participar de seu monólogo. Além disso, o jovem não aceita passivamente a presença do outro, ele discute com ela, a questiona, enfim polemiza com ela.

É assim consolidado outro elemento constitutivo para confirmar a polifonia na obra do autor russo, posto que, ao depreendermos vários programas narrativos e estes estarem, muitas vezes, em relação polêmica, é confirmada uma determinada autonomia entre os atores, bem como uma confluência fórica, já explicitada no nível fundamental. Isso nos permite dizer que o sincretismo de papéis actanciais entre os atores e a polêmica entre seus programas narrativos geram um campo dialógico, por excelência. Esse campo se concretiza discursivamente, visto que os atores apresentam papéis actanciais distintos, não convergentes em um mesmo programa, sendo o diálogo uma forma de esses atores coexistirem nos seus respectivos programas narrativos. Por conseguinte, Raskólnikov não instaura o papel temático nem de herói épico nem de anti-herói. Sustentam-se, assim, no nível narrativo, a 
mistura de papéis actanciais e a coabitação de programas narrativos distintos e possíveis, o que é corroborado pela confluência fórica do nível profundo.

No nível discursivo, onde é constatada a realização concreta da polifonia, verificamos que ela se constitui por meio de uma multiplicidade de vozes sociais, de temas e de figuras que se entrechocam e que não é comandada por uma voz soberana; antes, tem a possibilidade, segundo a trama nuclear de Raskólnikov, de participar do grande diálogo promovido pela tessitura discursiva da obra. Esse conjunto de vozes pode ser apreendido nos dois trechos que apresentamos.

No primeiro trecho, Raskólnikov, por meio de uma autoanálise, exige um posicionamento de si mesmo, mesmo assim, ele convoca um outro para dialogar consigo, como podemos observar pelo vocativo "meu caro senhor" e pela reminiscência do ator Marmieládov.

No segundo, Zamiótov, Razumkhín e o sujeito coletivo "os policiais" são todos instâncias convocadas, vozes, isto é, posicionamentos ideológicos, que são convocados e questionados por Raskólnikov. Tanto é assim que o protagonista planeja seu percurso de fuga em função das possíveis reações dessas vozes convocadas: "E o que Zamiótov veio fazer aqui? Para que Razumíkhin o trouxe aqui? [...] Vão achar! Razumíkhin acha [...] Eu só precisava descer a escada! Mas lá estão os guardas deles, os policiais!" (DOSTOIÉVSKI, 2009, p. 140).

Portanto, temos, no nível discursivo, mais um elemento constitutivo que compõe e auxilia a depreensão da polifonia: as vozes polêmicas do discurso e seu arranjo polifônico. Arranjo polifônico, porque, nesse nível, observamos concretamente, retomando a definição bakhtiniana, uma multiplicidade de vozes imiscíveis, plenivalentes e independentes.

Retomando os outros elementos constitutivos que evidenciamos, podemos dizer que essas vozes só se constituem no nível discursivo desse modo, porque são sustentadas pela determinada autonomia dos atores, evidenciada pela confluência fórica no nível fundamental; e pelo campo dialógico constituído por meio do sincretismo dos papéis actanciais e do desdobramento entre os diversos programas narrativos no nível narrativo.

Somando todos esses fatores, podemos depreender que a trama de Crime $e$ castigo é caracterizada como polifônica, porque, como pudemos observamos nos trechos citados, Raskólnikov convoca várias vozes as quais são perceptíveis e plenivalentes. Ou seja, diferenciam-se da do protagonista e possuem igual força se comparadas à voz e ao posicionamento de Raskólnikov, visto que ele as considera para poder agir. $\mathrm{O}$ ator Raskólnikov subsume ainda vários papéis actanciais na narrativa, o que sustenta a maleabilidade do ator polifônico.

Por conseguinte, no modo de presença dos atores de Crime e castigo, principalmente no de Raskólnikov, notamos uma exacerbação de suas consciências e das ambiguidades de suas relações. Assentados na teoria semiótica e em seus recursos analíticos, compreendemos que há uma recorrência no texto de uma organização dos conteúdos que pode ser formulada como o correlacionamento de duas categorias binárias de semas contraditórios ou contrários que coexistem no seu modo de presença, o que dá o efeito de mistura na construção estilística do ator. Por isso, asseveramos Raskólnikov como um herói da mistura.

A partir dessa análise, notamos a confirmação da reflexão de Bakhtin (1997, p. 4): "a multiplicidade de vozes e consciências independentes e imiscíveis e a autêntica polifonia de vozes plenivalentes constituem, de fato, a peculiaridade dos romances de Dostoiévski”. Portanto, através do estudo do percurso gerativo do sentido proposto por 
Greimas e Courtés (2008), delineamos alguns elementos constitutivos do efeito de sentido de polifonia.

\section{Considerações finais}

Entrar na cosmovisão polifônica não é tarefa fácil. Acostumados com medidas newtonianas, com precisão euclidiana, ficamos confusos diante da problematização teórica da multiplicidade de vozes e seu arranjo equipolente. Além disso, Dostoiévski não é um autor de páginas calmas e retilíneas, isto é, com passagens claras e com planos narrativos sequenciais. $\mathrm{O}$ autor russo exige de seu leitor atenção aos detalhes e fôlego para os parágrafos tensos e conturbados. As histórias dostoievskianas se cruzam, um personagem nunca está só, ele está em relação a outro, e o outro, por sua vez, está em relação àquele outro, e assim por diante.

Crime e castigo, como objeto de estudo, justifica-se porque traz uma estrutura peculiar. É diferente de qualquer outro romance do gênero policial, posto que é um romance polifônico. Raskólnikov também é peculiar: não é um criminoso, nem um inocente cidadão. $\mathrm{O}$ jovem é um paradoxo da modernidade. Daí surgiu o nosso interesse em estudar como esse ator do enunciado se relacionava com o mundo ao seu redor.

O objetivo principal desta pesquisa foi estudar, por meio da análise semiótica, os elementos constitutivos da polifonia no romance de Dostoiévski, tomando como ponto de partida esse romance e seu protagonista. Como resultado, demonstramos, pela teoria semiótica, que a polifonia pode ser considerada como um efeito de sentido depreensível desde as estruturas profundas até sua manifestação no nível discursivo.

Desse modo, por meio do arcabouço teórico da semiótica, foi-nos possível depreender, no romance Crime e castigo, que o efeito de sentido de polifonia é construído, principalmente, a partir de três elementos constitutivos a saber: (i) uma confluência fórica no nível fundamental; (ii) um campo dialógico exacerbado definido pela coabitação e divergência de diversos e distintos programas narrativos no nível narrativo e (iii) uma multiplicidade de vozes imiscíveis e plenivalentes resultantes dos posicionamentos ideológicos distintos dos atores do enunciado que estão em relação de polêmica principalmente.

Apresentados esses resultados parciais de uma pesquisa ainda em andamento, podemos dizer que a semiótica da Escola de Paris vem ao encontro da filosofia bakhtiniana para também conectar-se à proposta do filósofo russo. Portanto o que este estudo, ao abordar duas frentes teóricas distintas e até conflitantes em certos pontos, comprovou foi que é possível e proveitoso operacionalizar o conceito bakhtiniano de polifonia com base no rico instrumental da semiótica francesa.

\section{REFERÊNCIAS}

BAKHTIN, M. M. Estetika sloviésnovo tvórchestva. Ed. S. G. Bocharov. Moscou: Iskusstvo, 1979 (Coleção Russa).

Problemas da poética de Dostoiévski. Trad. Paulo Bezerra. Rio de Janeiro: Forense Universitária, 1997. 
VOLOCHÍNOV, V. N. Marxismo e filosofia da linguagem: problemas fundamentais do método sociológico da linguagem. Trad. Michel Lahud e Yara Frateschi. 13. ed. São Paulo: Hucitec, 2009.

Para uma filosofia do ato responsável. Trad. Valdemir Miotello e Carlos Alberto Faraco. São Carlos: Pedro e João Editores, 2010.

BARROS, D. L. P. Teoria semiótica do texto. 4. ed. São Paulo: Ática, 2005.

. Dialogismo, polifonia e enunciação. In: BARROS, D. L. P. de.; FIORIN, J. L. (Orgs.). Dialogismo, polifonia, intertextualidade. 2. ed. São Paulo: Edusp, 2011. p. 1-10.

BEZERRA, P. Nas sendas de Crime e castigo. In: DOSTOIÉVSKI, F. M. Crime e castigo. Trad. Paulo Bezerra. 6. ed. São Paulo: Editora 34, 2009. p. 7-13.

BRAIT, B.; CAMPOS, M. I. B. Da Rússia czarista à web. In: BRAIT, B. (Org.). Bakhtin e o Círculo. São Paulo: Contexto, 2009. p. 15-30.

CLARK, K.; HOLQUIST, M. Mikhail Bakhtin. Cambrigde (Massachussets): Harvard University Press, 1984.

DISCINI, N. Semiótica: da imanência à transcendência (questões de estilo). Revista Alfa. São Paulo, v. 53, n. 2, 2009. p. 595-617. Disponível em: <http://seer.fclar.unesp.br /alfa/article/view/2133>. Acesso em: 03 mar. 2013.

. Carnavalização. In: BRAIT, B. (Org.). Bakhtin: outros conceitos-chave. São Paulo: Contexto, 2008, p. 53-94.

DOSTOIÉVSKI, F. M. Crime e castigo. Trad. Paulo Bezerra. 6. ed. São Paulo: Editora 34, 2009.

DUCROT, O. O dizer e o dito. Trad. Eduardo Guimarães. Campinas: Pontes, 1987.

FRANK, J. Dostoiévski: os anos milagrosos (1865-1871). Trad. Geraldo Gerson de Souza. São Paulo: Edusp, 2003.

GREIMAS, A. J; COURTÉS, J. Dicionário de semiótica. Trad. Alceu Dias Lima et al. São Paulo: Contexto, 2008.

GREIMAS, A. J. Du sens II: essais sémiotiques. Paris: Seuil, 1983.

HJELMSLEV, L. Prolegômenos a uma teoria da linguagem. Trad. José Teixeira Coelho Netto. São Paulo: Perspectiva, 1975.

MORSON, G. S.; EMERSON, C. Mikhail Bakhtin: criação de uma prosaística. Trad. Antonio de Pádua Danesi. São Paulo: Edusp, 2008.

SAUSSURE, F. de. Curso de linguística geral. Trad. Antônio Chelini, José Paulo Paes e Izidoro Blikstein. São Paulo: Cultrix, 1970.

TODOROV, T. Mikhail Bakhtin: the dialogical principle. Trad. Wlad Godzich. Mineapolis: University of Minnesota Press, 1984.

ZILBERBERG, C. Elementos da gramática tensiva. Trad. Ivã Lopes, Luiz Tatit e Waldir Beividas. São Paulo: Ateliê Editorial, 2011.

Recebido em: 09.03.13

Aprovado em: 20.05.13 